\title{
Initial Experience with Digital Patient Briefing in Computed Tomography
}

\section{Erste Erfahrungen mit einer mobilen digitalen Patientenaufklärung in der Computertomografie}

Authors

Babak Alikhani ${ }^{1,2}$, Bennet Hensen², Arne Grosser², Maria Inés Cartes Febrero³, Markus von Bestenbostel ${ }^{3}$, Frank K. Wacker², Hans-Jürgen Raatschen²

Affiliations

1 Center for Radiology and Nuclear Medicine, DIAKOVERE gGmbH, Hannover, Germany

2 Institute for Diagnostic and Interventional Radiology, Hannover Medical School, Hannover, Germany

3 Department of Strategic Risk Management and PatientSafety, Hannover Medical School, Hannover, Germany

Key words

digital patient briefing, computed tomography

received 12.11 .2017

accepted 04.09.2018

Bibliography

DOI https://doi.org/10.1055/a-0748-5962

Published online: 17.10.2018

Fortschr Röntgenstr 2019; 191: 540-546

(c) Georg Thieme Verlag KG, Stuttgart · New York

ISSN 1438-9029

Correspondence

Dr. Babak Alikhani

Zentrum für Radiologie und Nuklearmedizin,

DIAKOVERE, gGmbH, Marienstr. 72 -90,

30171 Hannover, Germany

Tel.: ++ 49/5 11/2892435

babak.alikhani@diakovere.de

\section{ABSTRACT}

Purpose To assess digital patient briefing as an alternative to conventional paper documentation.

Materials and Methods 502 patients with a planned computed tomography (CT) examination were selected for digital patient briefing using the E-ConsentPro software from Thieme Compliance on an iPad by Apple (Cupertino, California, USA). For the analysis, three age groups were formed. The time required for the patient briefing, the number of open questions as well as the time needed for discussion with physicians were determined. Student's t-test was performed to assess statistical significance.

Results There was no significant difference between patient age and briefing time which was about 20 minutes on aver- age. The number of open or unclear questions increased with patient age. While patients younger than 30 years of age had about 2 open questions, patients over 30 and 60 years had about 4 and 5 questions, respectively. The total time needed for discussion with physicians was less than 2 minutes on average. A significant difference in the time required for discussion with physicians could not be observed between the individual age groups.

Conclusion Tablet-based digital briefing allows the storage of patient documents with reasonable time and effort. Furthermore, it minimizes the risk of data loss.

\section{Key Points}

- Tablet-based digital patient briefing in computed tomography can be performed with reasonable time and effort.

- The time required for tablet-based patient briefing is independent of patient age.

- The cost-benefit analysis presents a significant improvement in digital patient briefing compared to the paperbased process.

\section{Citation Format}

- Alikhani B, Hensen B, Grosser A et al. Initial Experience with Digital Patient Briefing in Computed Tomography. Fortschr Röntgenstr 2019; 191: 540-546

\section{ZUSAMMENFASSUNG}

Ziel Die Möglichkeit der digitalen Aufklärung von Patienten wurde im Rahmen eines Pilotprojekts evaluiert.

Material und Methoden Für die vorliegende Arbeit wurden 502 konsekutive Patienten ausgewählt, die in der Computertomografie (CT) untersucht werden sollten. Die digitale Aufklärung erfolgte mit der Software E-ConsentPro der Firma Thieme Compliance auf einem iPad. Die Patienten wurden in 3 Altersgruppen unterteilt. Die Auswertung beschränkte sich auf die Ermittlung der Gesamtdauer der Patientenaufklärung, der offenen oder unklaren Fragen sowie des Zeitaufwands für ein Aufklärungsgespräch mit dem Arzt. Zur Prüfung von signifikanten Unterschieden wurde der t-Test durchgeführt.

Ergebnisse Unabhängig vom Alter bearbeiteten die Patienten den digitalen Aufklärungsbogen im Mittel ca. 20 Minuten. Die Anzahl der offenen oder unklaren, noch mit dem aufklärenden Arzt zu besprechenden Fragen nahm nicht signifikant 
mit dem Patientenalter zu. Während Patienten unter 30 Jahren vor dem Arztgespräch ca. 2 offene Fragen hatten, hatten Patienten über 60 Jahre ca. 5 offene Fragen. Patienten zwischen 30 und 60 Jahren hatten noch ca. 4 Fragen, die mit dem Arzt besprochen werden sollten. Die Gesamtdauer eines Aufklärungsgesprächs mit dem Arzt betrug im Mittel unter 2 Minuten. Signifikante Unterschiede im Zeitaufwand für das ärztliche Aufklärungsgespräch konnten zwischen den einzelnen Altersgruppen nicht festgestellt werden.
Schlussfolgerung Die Tablet-basierte digitale Aufklärung ermöglicht unabhängig vom Patientenalter und der Anzahl der offenen Fragen vor dem Arztgespräch eine mit vertretbarem Zeit- und Arbeitsaufwand zu realisierende rechtssichere Ablage der Dokumente, bei der das Risiko des Datenverlusts durch die Logistik und Archivierung von Patientenunterlagen reduziert werden kann.

\section{Introduction}

On February 25, 2013, the German Bundestag enacted the "Act to Improve Patient Rights" dated February 20, 2013 [1]. According to $\S 630$ e Paragraph 2, patients are to be given copies of documents signed in connection with patient briefing and informed consent.

Patient briefing is a regular part of the clinical routine. It is important for "informed patients" to have a good understanding of planned examinations and the associated risks. Patient briefing is currently usually performed in writing on paper. Tablet computers, whose potential uses in medicine have already been examined in various studies [2-8], have made it possible to replace conventional briefing documentation with digital patient briefing.

The goal of this pilot project is to evaluate the technical implementation of digital patient briefing and its use in the clinical routine as well as personnel requirements. Moreover, an analysis of the time requirement provides information regarding differences in briefing times and costs between digital and paper-based processes.

\section{Materials and Methods}

\section{Digital patient briefing}

Digital patient briefing was performed using the software E-Consent Pro from Theme Compliance [9] installed on an Apple i Pad R2 (Cupertino, CA, USA) running operating system OS 10. This tablet-based software can be used for recording patient information and for individualized patient briefing. At the time of a patient's examination, an order for the requested radiology service, in our case the CT examination, is available in the HIS for the patient. Using a link in the HIS, a print order for a paper-based patient briefing form can be generated or the patient can be assigned to digital patient briefing. In the case of assignment to digital patient briefing, an 8-digit code is generated and is to be entered by the patient prior to beginning to use of the tablet. However, for the sake of practicality, at our institute this code is not entered by the patient but rather by an administrative employee who then hands the tablet to the patient. This process step is referred to as "assignment". Since the software does not contain the same level of examination information as provided in paper-based patient briefing and patient medical history forms, we give the patient the tablet as well as a printout of the examination information. The patient is greeted by the tablet by name and must provide authentication by entering his date of birth. Upon successful authentication, the patient can begin answering the questions. All twelve questions must be answered, see $>$ Tab. 1. Depending on the responses, the patient may be required to answer additional secondary questions. In the case of open questions or ambiguities, the patient can select the option "discuss with physician". The software provides the physician with an overview of all patient briefings currently in progress with the status "started", "in progress", and "complete". As a result, the physician who is exclusively responsible for reviewing the indication, defining the examination protocols, and briefing patients at our institute always has a detailed overview of the status of waiting patients. As soon as a patient achieves the status "complete", the physician can select the relevant patient on his tablet in order to view all questions with the patient's corresponding responses. Open questions are marked separately for faster processing. The physician then has a discussion with the patient and can enter comments and notes directly on the tablet.

The following actions are automatically digitally logged with a time stamp. Assignment of the form, opening by the patients, processing by the patient, completion by the patient, opening by the physician, processing by the physician, completion by the physician, signing by the patient, signing by the physician, time of generation of the PDF/A document. Until completion by the physician, changes can be made to the document and are provided with a corresponding time stamp. Whether the action was performed in a patient or physician context is noted for every time stamp. Therefore, there are two users, namely the patient and the physician. The software currently does not have a feature for noting processing in a patient context by someone other than the patient, e.g. a family member or employee. The patient provides a digital biometric signature on the tablet to consent to examination. A signature field is displayed for this purpose on the tablet at the end of the digital briefing and is signed by both the physician and the patient using a special pen. In addition to the signature, the pressure and angle of the pen are recorded and digitally stored. This information is generally considered legally secure. Signing is only possible after all open questions have been discussed with the physician. By signing, the patient confirms his consent to (or refusal of) CT examination. This process is thus comparable with the paper documents currently used for patient briefing and recording of the medical history. Once the physician and patient have signed, further processing of the document or manipulation of the data is no longer possible. The digital document is archived with the responses to the medical history questions, the individual comments of the physician, and the digital 
- Table 1 Questions included in the digital patient briefing and number of patients unable to answer these questions on their own.

\begin{tabular}{|c|c|c|}
\hline & Question & $\begin{array}{l}\text { Number of } \\
\text { open questions }\end{array}$ \\
\hline 1 & Height/weight & 16 \\
\hline \multirow[t]{2}{*}{2} & Do you currently take medication on a regular basis? & 66 \\
\hline & If yes, please describe. & 9 \\
\hline 3 & Do you have seasonal allergies, allergic asthma, or an intolerance to certain substances? & 8 \\
\hline $\mathrm{i}$ & If yes, please describe. & 4 \\
\hline \multirow[t]{2}{*}{4} & Do you currently have or have you ever had an infectious disease? & 10 \\
\hline & If yes, please describe. & \\
\hline 5 & Do you have a gastrointestinal disease or external/internal hemorrhoids or strictures in the anal region? & 14 \\
\hline $\mathrm{i}$ & If yes, please describe. & 8 \\
\hline \multirow[t]{2}{*}{6} & $\begin{array}{l}\text { Have you been diagnosed with a metabolic disease (e. g. gout, diabetes) or a disease involving a major organ } \\
\text { (e. g., kidney, heart, vascular system, lung, liver, nervous system)? }\end{array}$ & 16 \\
\hline & If yes, please describe. & 6 \\
\hline 7 & Have you been diagnosed with other benign or malignant diseases that can affect kidney function? & 35 \\
\hline $\mathrm{i}$ & If yes, please describe. & \\
\hline 8 & Do you currently have or have you ever had thyroid disease? & 15 \\
\hline $\mathrm{i}$ & If yes, please describe. & \\
\hline 9 & Have you ever undergone a CT or MRI scan or X-ray examination of the body region to be examined now? & 17 \\
\hline i & If yes, when (year), where (facility), which body region/organ? & 83 \\
\hline ii & If yes, was contrast agent used? & 28 \\
\hline iii & If yes, did you experience side effects (e. g. circulatory changes, shock, rash)? & 22 \\
\hline iv & If yes, please describe. & \\
\hline 10 & Have you ever undergone an operation in the body region to be examined now? & 17 \\
\hline i & If yes, please describe. & 14 \\
\hline 11 & Are you claustrophobic (fear of tight or enclosed spaces) or are you prone to panic attacks? & 8 \\
\hline 12 & Additional questions for women: Could you be pregnant? Are you breastfeeding? & 2 \\
\hline
\end{tabular}

signature of the patient and physician including the corresponding time stamps as a PDF/A document in the digital patient file. The PDF/A document is initially temporarily stored on a central server in the IT department and is then automatically assigned to the patient on the basis of the stored case ID and patient ID in the digital archive used hospital-wide. Prior to implementation of this internal solution, this process was checked for accuracy by employees in the IT department and the central patient archive. At the same time, a copy of the patient briefing documents is printed out on a local networked printer and is provided directly to the patient. To ensure data protection in the case of loss or theft, data is not stored on the device.

\section{Data analysis}

For this study performed in the period 3-9/2015, the data of 502 consecutive patients briefed with the help of the E-Consent Pro software for a diagnostic CT examination was evaluated. A prerequisite for inclusion was mastery of the German language. Discus- sions with patients receiving care or prior to CT-guided interventions were excluded from the analysis. Further selection of the patient population based on disease spectrum was not performed. In addition to emergency situations, many examination were performed in our areas of specialization, i. e., in the framework of staging and cardiovascular issues. Due to the organizational separation between radiology and neurophysiology, neurophysiology issues were seen in only a few patients. Under the assumption that younger patients have a higher affinity for tablet computers and thus have fewer reservations and technical difficulties using tablets, patients were divided into three age groups. Data analysis was performed separately for each group. The first group (A) was comprised of 40 patients under the age of 30 . The second group (B) included 220 patients between 30 and 60 years old. The last group (C) was comprised of 242 patients over the age of 60 .

The analysis was limited to the quantitative determination of three aspects: 
- What was the total patient briefing time from opening to signing?

- How many open or unclear questions did the patient need to discuss with the physician?

- What was the total time needed for discussion with the physician prior to diagnostic CT examination?

The t-test was performed to check for significant differences. A p-value of less than 0.05 was statistically significant.

\section{Results}

The average age of the 502 patients was $58 \pm 17$ years. The histogram of the age groups is shown in $\mathbf{F i g . 1}$. The average age of groups A, B, and C was $21 \pm 7,49 \pm 8$ and $71 \pm 7$ years, respectively.

- Fig. 2 shows the total time needed for patient briefing as a function of the patient's age. The time needed for patient briefing was independent of patient age (increase $=-2.99 \cdot 10^{-5}$, $R^{2}=2.22 \cdot 10^{-3}$ ).

The time needed for patient briefing was $19.2 \pm 12.5,21.4$ \pm 17.0 and $19.4 \pm 14.8$ minutes for the individual groups as shown in $>$ Fig. 3. There was no significant difference in the briefing times of all groups ( $p=0.339)$.

The patient briefing included twelve questions. Depending on the responses to the main questions, patients may be required to answer up to twelve additional secondary questions. Of the 502 evaluated patients, 224 had open questions prior to the discussion with the physician. Clarification was required particularly with respect to questions as to whether an operation had already been performed in the body region to be examined ( 83 patients) and regarding the regular use of medications (66 patients). The other open questions comprised a percentage of less than $10 \%$. All patient briefing questions are listed in the appendix. Patients with more than 10 open questions were not included in the evaluation (33 patients) since it must be assumed that there was a fundamental issue with comprehension. 32 of the 33 hospitalized patients had reduced alertness and were unable to answer the questions independently. 1 of the 33 patients was young with a newly diagnosed advanced-stage tumor. We interpreted her refusal to answer the questions on the tablet as a coping mechanism.

The number of questions requiring discussion with the physician increased with the patient's age. While patients in group A had an average of $1.9 \pm 1.3$ open questions, the number of questions requiring clarification was $3.6 \pm 3.9$ in group $B$ and $4.8 \pm 5.3$ in group $C$. The results of the questions to be discussed are shown in $>$ Fig. 4. A significant difference regarding the number of open or unclear questions was not observed between the three groups $(p=0.051)$.

The time needed by the physician to answer or process open or unclear questions for all groups is shown in - Fig. 5. The corresponding averages for groups $A, B$ and $C$ were $1.5 \pm 1.3$, $1.7 \pm 1.8$ and $2.0 \pm 2.2$ minutes indicating a time requirement independent of patient age $(p=0.449)$.

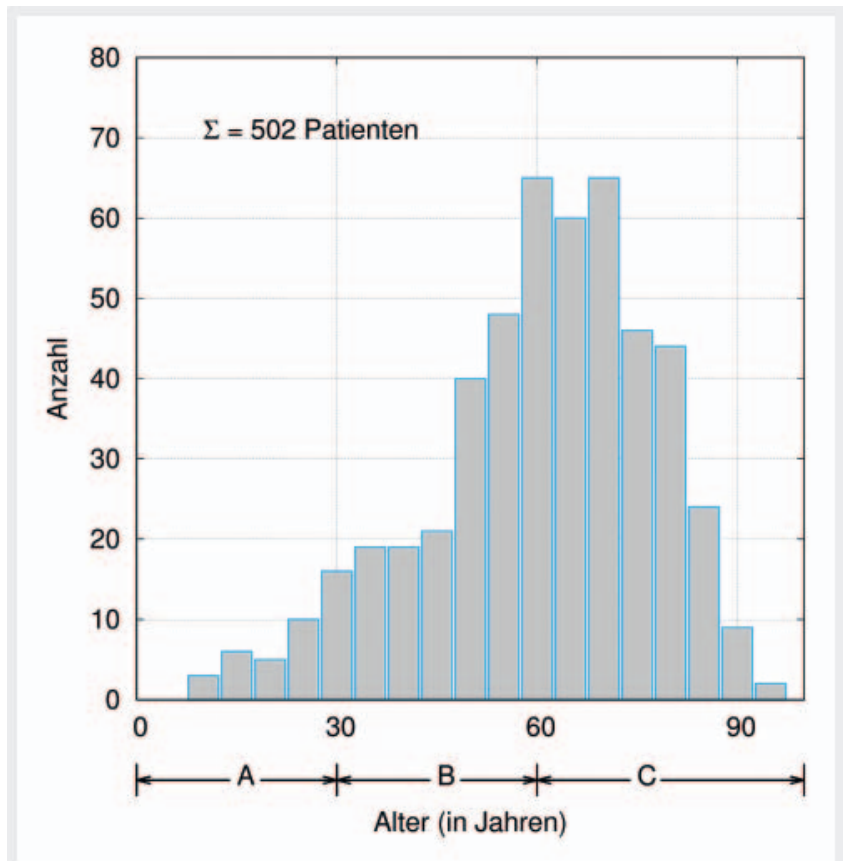

- Fig. 1 Histogram of age groups. Group A: age < 30 years, group B: $30-60$ years, group C: age $>60$ years.

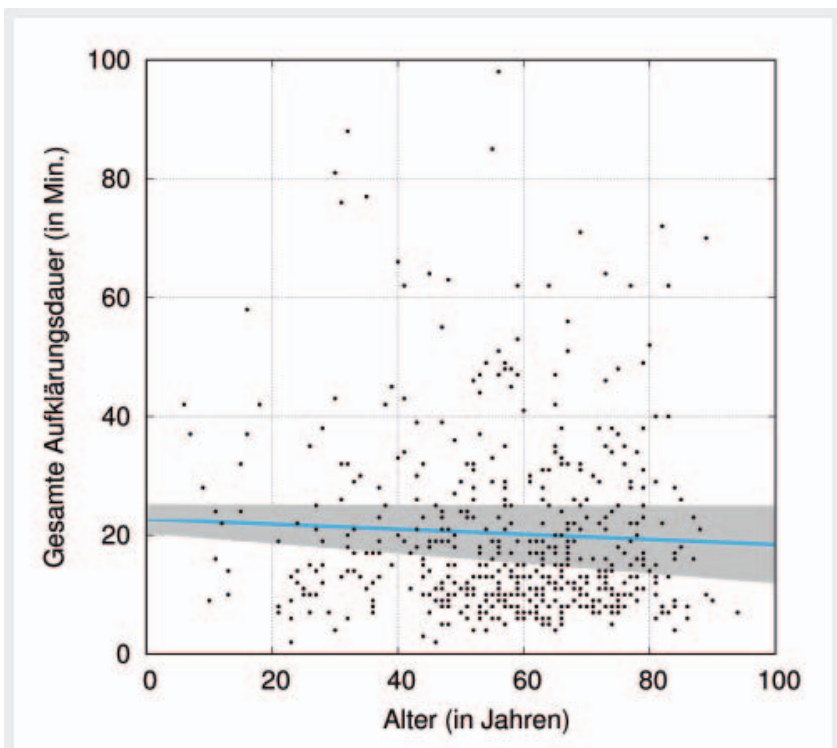

- Fig. 2 Total time needed for patient briefing as a function of the patient's age.

\section{Discussion}

Although the performance of digital patient briefing prior to MRI examinations has been evaluated in various studies [4, 5], no corresponding data regarding digital patient briefing prior to CT examinations has been published to date. In our opinion a decisive difference compared to MRI is the higher rate of CT examinations due to the typically shorter examination time. Particularly in the 


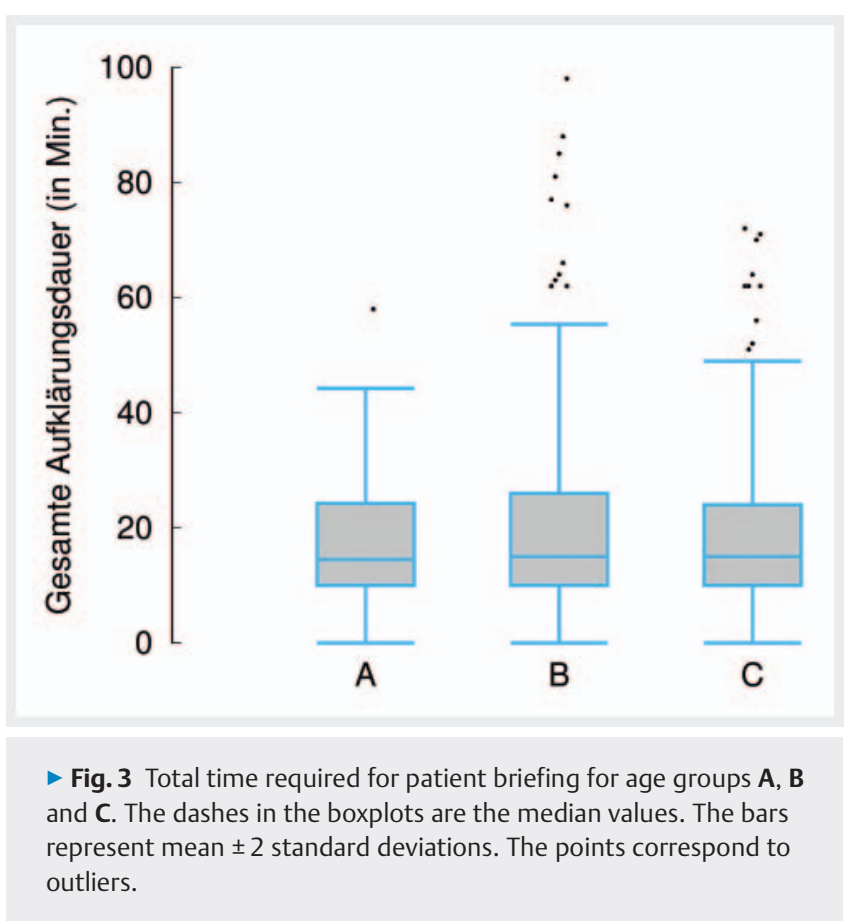

case of parallel operation of multiple CT units, it has been our experience that the patient briefing process can represent a bottleneck, thus extending wait times for patients and resulting in unit downtime. Therefore, optimization of the patient briefing process could greatly improve work flows in computed tomography. Consequently, we decided to conduct a pilot project to evaluate tablet-based digital patient briefing in the area of computed tomography. The present study provides the results of this project.

The total briefing time from assignment to legally secure signature was approximately 20 minutes on average and did not differ significantly between the three age groups The total time for discussion with the physician including explanation of typical and individual risks as well as clarification of open questions was less than 2 minutes on average. Questions regarding previous operations and medications were most common. Our data analysis showed a trend toward more open questions with increasing age although the defined level of significance was just barely exceeded ( $p=0.051$ ). A different age group categorization may have shown significant differences between the groups regarding open questions.

At our institute, the time needed for paper-based patient briefing was determined prior to the introduction of digital patient briefing on the basis of a sample of 100 patients. In concordance with the digital processes evaluated in this study, the preceding analysis also included the time from arrival of the patient in the CT waiting area to archiving of the patient briefing documents. The time needed for this was approximately 39.8 minutes of active work time or up to 46.8 minutes in the case of incomplete or incorrect patient briefing documents or technical problems during archiving. Passive time during which documents were waiting to be retrieved by a patient archive employee was not included in the time analysis. We expected an average time savings of 6.5 minutes compared to the paper-based briefing process as a result of the automation of the storage of briefing documents in the digital pa-

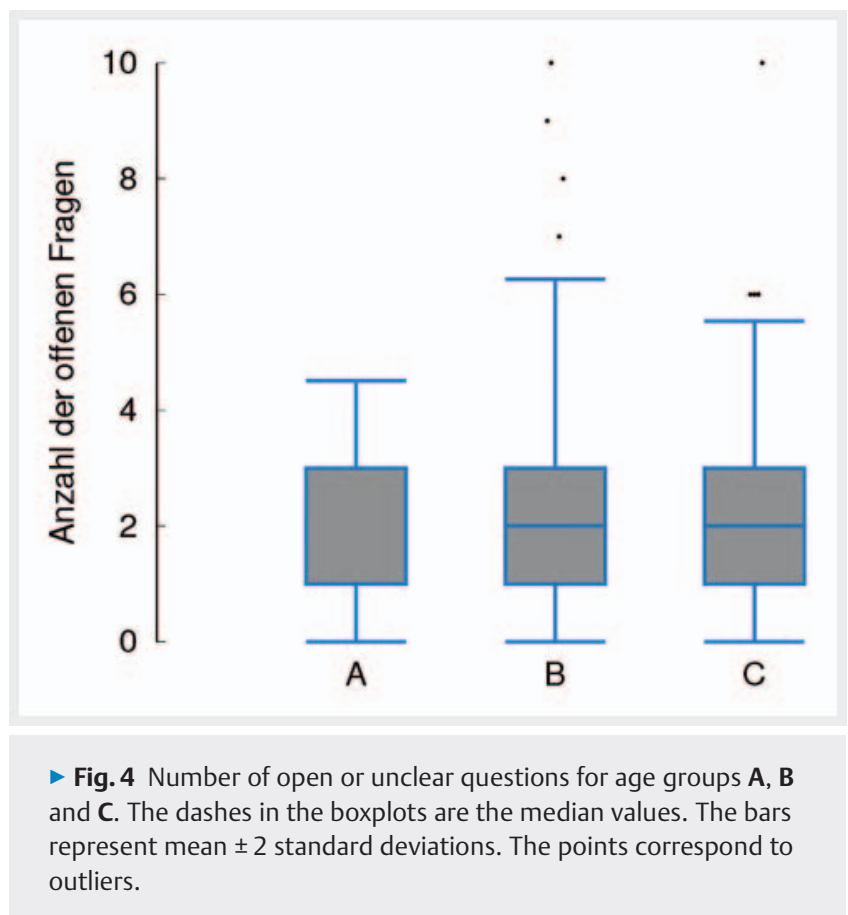

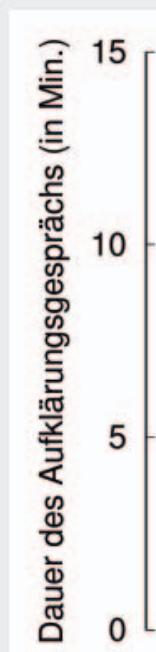

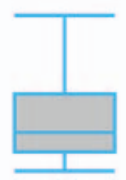

A

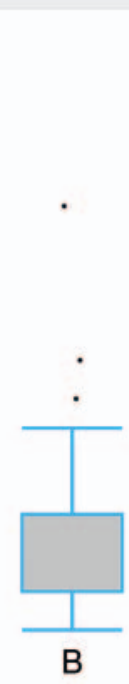

- Fig. 5 Total time needed for the processing of open questions and discussion with the physician for age groups $\mathbf{A}, \mathbf{B}$ and $\mathbf{C}$. The dashes in the boxplots are the median values. The bars represent mean \pm 2 standard deviations. The points correspond to outliers.

tient file. Thus, the tablet-based technology presented here with a total briefing time of approx. 20 minutes is not only significantly shorter than the total time for the paper-based method but is also $40 \%$ shorter than the value determined in the time requirement analysis. The lower personnel time requirement (medical employees, radiographers) and the potential elimination of personnel costs in the patient archive result in a reduction in personnel costs of approx. $20 \%$. In comparison, the one-time investment costs for the purchase of tablets and digital pens are of minimal consequence. The highest investment costs can be expected in the 
case of expansion of the WLAN network to include multiple access points prior to establishing the digital briefing process.

Every patient received a copy of the patient briefing documents. Due to the option not only to generate the PDF document but also to initiate printing of a copy via the "air print" technology upon completion of the patient briefing process, we found the process presented here to be feasible. Moreover, the printer was in the immediate vicinity of the area in which patient briefing was performed so that the medical employees did not have to walk far. However, in our experience, most patients do not want a copy of the patient briefing documents. Therefore, we currently explicitly ask patients prior to conclusion of the discussion with the physician if they want a copy and confirm as applicable in a field provided on the digital briefing document for this purpose that a copy was not desired. This elimination of some copies results in a further, albeit minimal, cost savings.

We attributed the greater number of open questions with increasing patient age to the fact that the underlying diseases are more complex and may affect multiple organ systems. Such complex medical information may be more difficult for older people to record so that more questions remain open or patients are unsure how to correctly answer questions. However, this does not have a significant effect on the time needed by the physician to clarify questions, and this value was comparable with the younger age groups.

The briefing of underage patients was not given separate consideration in the present study. Since the rule at our institute is to brief patients under the age of 16 years in the presence of a legal guardian, it must be expected that some questions were answered by the minor and some by the legal guardian. This cannot by definitively clarified since the software only allows differentiation between patient/legal guardian/caregiver on the one side and the physician on the other side. The software also cannot record whether older patients received assistance from younger family members or non-medical personnel. The extent to which these points affect the total patient briefing time, the time for discussion with the physician, and the number of open questions remains unclear. However, a similar problem regarding underage and older patients can probably be expected in the case of paper-based patient briefing.

Following the digital patient briefing process, we surveyed 100 patients who had previously participated in paper-based patient briefing for a diagnostic CT examination at least once. $83 \%$ of these patients preferred the digital process to the paper-based method. Moreover, $62.5 \%$ of medical employees and radiographers rated the digital process as superior, which was largely due to the lower time requirement.

As a result of the time savings and the high acceptance of digital patient briefing among patients and employees in combination with automated and legally secure archiving that is largely free of errors like document loss, we decided to replace paperbased patient briefing with the tablet-based digital process in computed tomography following the pilot phase.

\section{Clinical relevance}

Digital patient briefing is accepted by patients of different age groups as well as by employees and helps to optimize organizational processes in radiology with the efficient use of personnel.

\section{Conflict of Interest}

The authors declare that they have no conflict of interest.

\section{References}

[1] Gesetz zur Verbesserung der Rechte von Patientinnen und Patienten vom 20. Februar 2013, 2013. Bundesgesetzblatt Jahrgang. 2013. Teil I Nr. 9, ausgegeben zu Bonn am 25. Februar 2013

[2] John S, Poh ACC, Lim TCC et al. The iPad Tablet Computer for Mobile On-Call Radiology Diagnosis? Auditing Discrepancy in CT and MRI Reporting. J Digit Imaging 2012; 25: 628-634

[3] Zekely A, Talanow T, Bagyi P. Smartphones, tablets and mobile applications for radiology. Eur J Radiol 2013; 82: 829-836

[4] Schlechtweg PM, Hammon M, Heberlein C et al. Can the documented patient briefing be carried out with an iPad app? J Digit Imaging 2013; 26: $383-392$

[5] Schlechtweg PM, Hammon M, Giese D et al. iPad-Based Patient Briefing for Radiological Examinations - a Clinical Trial. J Digit Imaging 2014; 27: 479

[6] Toomey RA, Rainford LA, Leong DL et al. Is the iPad Suitable for Image Display at American Board of Radiology Examinations? Am J Roentgenol 2014; 203: $1028-1033$

[7] Caffery LJ, Manthey KL, Sim LH. The effect of time in use on the display performance of the iPad. Br J Radiol 2016; 89: 20150657

[8] Park JH, Kim YK, Kim B et al. Diagnostic performance of smartphone reading of the coronary $C T$ angiography in patients with acute chest pain at ED. Am J Emerg Med 2016; 34: 1794-1798

[9] Software E-ConsentPro. https://www.thieme-compliance.de/de/ softwaree-consentpro/ 